Nevşehir Bilim ve Teknoloji Dergisi TARGíd Özel Sayı 364-371 2016

DOI: 10.17100/nevbiltek.211024

URL: http://dx.doi.org/10.17100/nevbiltek.211024

\title{
Orta Anadolu Bölgesi İllerinde Tarımsal Mekanizasyon Düzeyinin Yıllara Göre Değişimi
}

\author{
Cevdet SAĞLAM ${ }^{1}$, Zeynel Abidin KUŞ ${ }^{1, *}$ \\ ${ }^{1}$ Erciyes Üniversitesi, Seyrani Ziraat Fakültesi, Biyosistem Mühendisliği Bölümü, Kayseri \\ Öz
}

Bu araştırmada, Orta Anadolu Bölgesinde bulunan Kayseri, Kırşehir, Nevşehir, Niğde, Sivas, Yozgat, Aksaray ve Kırıkkale illerine ait tarımsal mekanizasyon düzeyinin 2005-2014 yılları arasındaki değişimi belirlenmiştir. Orta Anadolu Bölgesi’nde ilgili yıllar arasındaki değişimin istatistiksel olarak ortaya konulması amacıyla her bir yıla ait traktör sayısı, biçerdöver sayısı, tarımsal aletmakina sayısı ve tarımsal mekanizasyon düzeyi göstergeleri hesaplanmıştır. 2005 ve 2014 yıllarındaki traktör sayısı 113823 ve 126128 adet, biçerdöver sayısı 2115 ve 3140 adet ve tarımsal alet-makine sayısı 806940 ve 900050 adettir. 2005 ve 2014 yılları mekanizasyon göstergeleri sırasıyla; ortalama traktör gücü 39,32 ve $40,38 \mathrm{~kW}$, ekilen tarım alana düşen traktör gücü 1,76 ve 2,18 kW/ha, 1000 ha alana düşen traktör sayısı 44,66 ve 53,90 adet, traktör başına düşen ekilen alan 22,39 ve 18,55 ha, ve 1000 ha alana düşen biçerdöver sayısı 0,83 ve 1,34 adet olarak belirlenmiştir.

Anahtar Kelimeler: Orta Anadolu, tarımsal mekanizasyon düzeyi, değişim

\section{Evaluation of the Agricultural Mechanization Level in the Provinces of Central Anatolia Region}

\begin{abstract}
The present study was conducted to investigate the evaluation of the agricultural mechanization level in the Central Anatolia Region covering Kayseri, Kırşehir, Nevşehir, Niğde, Sivas, Yozgat, Aksaray and Kırıkkale provinces for the years 2005-2014. To reveal the evaluation statistically, Central Anatolia Region's tractor number, harvester number, agricultural tool-machine number and agricultural mechanization level indicators for the related years have been calculated. For the years 2005 and 2014, the tractor numbers were 113823 and 126128, harvester numbers 2115 and 3140, while agricultural tool-machine numbers were 806940 and 900050. The 2005 and 2014 mechanization level indicators were defined as follows, respectively; average tractor power 39,32 kW and 40,38 kW, tractor power per cultivated area 1,76 kW/ha and 2,18 kW/ha, tractor number per 1000 ha area 44,66 and 53,90 cultivated area per tractor 22,39 ha and 18,55 ha, harvester numbers per 1000 ha area 0,83 and 1,34.
\end{abstract}

Keywords: Central Anatolia, agricultural mechanization level, evaluation

*e-mail: zkus@erciyes.edu.tr 


\section{Giriș}

Tarımsal mekanizasyon; tarım alanlarını daha sağlıklı hale getirmek, tarımsal üretim çeşitliliğini arttırmak ve tarımsal ürünlerin daha etkin ve çeşitli olarak kullanılmasını sağlamak gibi amaçların benimsendiği imalat sektörünün yatırım malları üreten alt sektörlerinden biri olarak tanımlanabilir [1]. Bir diğer tanımlamaya göre tarımsal mekanizasyon, tarımsal işlemlerin makina ve enerji kullanımıyla gerçekleştirilmesini ifade etmektedir. Tarımda makina kullanımı, diğer tarım teknolojisi uygulamalarından farklı olarak, verim artışını dolaylı olarak etkilemekte; kırsal kesimde yeni üretim yöntemlerinin uygulanmasını sağlamaktadır. Bu yönüyle diğer teknolojik uygulamaların etkinliğini ve ekonomikliğini artırmakta ve çalışma koşullarını iyileştirmektedir [2].

Tarım sektörü, gelişmekte olan tüm ülkelerde olduğu gibi, ülkemizde de ulusal ekonominin temelini oluşturmaktadır. Aktif nüfusumuzun yaklaşık \%35'i hala tarımsal üretimde çalışmaktadır. Hızla artan ülke ve dünya nüfusuna bağlı olarak beslenme, barınma ve giyim gibi alanlarda her geçen gün daha çok ve kaliteli hammaddeye ihtiyaç duyulması, buna bağlı olarak tarım alanlarında insan işgücüne duyulan gereksinim gibi unsurlar tarım sektörünün geleceği ve önemi hakkında fikir vermektedir [3].

Tarımsal faaliyetlerde üretim girdilerinin yaklaşı $\% 35$ 'ini mekanizasyon girdisi oluşturmaktadır. Buna rağmen mekanizasyon; tohum, gübre, ilaç ve yakıttan daha az önemli görülmekte ve yakıtın da bir mekanizasyon girdisi olduğu çoğu zaman gözden kaçmaktadır. Diğer yandan mekanizasyon araçlarının çoğunlukla eski teknolojiye sahip olması ürün verimini düşürmektedir. Mekanizasyona gerekli kaynağın aktarılmaması sonucunda; verimin ve ürün kalitesinin düşmesi, bakımonarım ve işletme masraflarının artması, gübreleme ve ilaçlama gibi uygulamaların yeterince hassas yapılamaması ve eskiyen makineler tarafından çevreye daha yüksek miktarda emisyon gazlarının salınması gibi insan ve çevre için oldukça olumsuz sonuçların meydana geleceği açıktır [4].

Tarımsal mekanizasyon düzeyini etkileyen temel unsurların başında tarım alanları ve makine varlıkları yer almaktadır. 2001 yılında yapılan tarım sayımına göre ülkemizde 1000 dekardan büyük araziye sahip işletme sayısı 4500 adet iken, 5000 dekardan büyük araziye sahip işletme sayısı sadece 57'dir. İşletmelerin üçte biri ortalama 20-50 dekar araziye sahiptir. Ülkemizde hız kazanan arazi toplulaştırma çalışmalarının bu noktada etkili olduğu ve olacağı öngörülmektedir. Yine 2001 yılında yapılan tarım sayımına göre ülkemizde yaklaşık 860 bin işletme kendi traktörüne sahipken, 1,2 milyon işletme kira ile traktör kullanmaktadır [5].

2001 yılı tarım sayımı verilerinin incelendiği bir çalışmada İç Anadolu bölgesinin en fazla traktör sayısına sahip bölge olduğu ortaya konulmuştur. Aynı çalışmada tarımsal mekanizasyon düzeyleri açıssından, bölgelerimiz içerisinde Marmara ve Ege Bölgeleri en yüksek düzeyde, Güneydoğu ve Doğu Anadolu Bölgeleri ise, en düşük oranlara sahip olduğu yer almaktadır. En az traktör kullanımına sahip bölgeler ise, Güneydoğu ve Doğu Anadolu bölgeleridir. İşlenen alan yönünden ise, traktör kullanımında olduğu gibi, ilk sırayı İç Anadolu Bölgesi almakta olup, bunu sırasıyla Güneydoğu Anadolu ve Marmara Bölgeleri izlemektedir [6]. Bu çalı̧̧mada amaçlanan; Orta Anadolu Bölgesi illerinde tarımsal mekanizasyon düzeyinde son on yılda meydana gelen değişiminin ortaya konulmasıdır.

\section{Materyal ve Metot}

Orta Anadolu bölgesi; Kayseri, Kırşehir, Nevşehir, Niğde, Sivas, Yozgat, Aksaray ve Kırıkkale illerini kapsamaktadır. 2014 yılında Orta Anadolu bölgesinde bulunan toplamda yaklaşık 3739 bin 
hektarlık tarım alanı Türkiye'deki toplam tarım alanının \% 9,69’unu oluşturmaktadır. Diğger yandan bölgeye ait yaklaşık 2339 bin hektarlık ekilen tarım alanı Türkiye’deki ekilen toplam tarım alanının \%14,82 ine karşılık gelmektedir.

Çalışmada kullanılan veriler, Türkiye İstatistik Kurumuna (TUİK) ait resmi internet sitesinden alınmıştır. Materyal olarak kullanılan veriler; toplam ve ekilen tarım alanlarını, traktör, biçerdöver ve alet-makine sayılarını ve traktör güç değerlerini içermektedir. Bu veriler arasından tarım alet ve makine sayılarının yüzde kaçının faal olarak kullanıldığı veya bunlara ait yıllık kullanım süreleri ayrıca rapor edilmediğinden yapılan istatistiksel değerlendirmelerde bu durumun dikkate alınması gerekmektedir. İlgili verilerin işlenmesi ile tarımsal mekanizasyon göstergeleri hesaplanmış ve gerekli değerlendirmeler tablo ve şekiller eşliğinde yapılmıştır. Tarımsal mekanizasyon düzeyinin belirlenmesinde ve değerlendirilmesinde literatürde genel olarak kabul gören göstergeler aşağıdaki verilmiştir [2,3,7].

G1: Birim ekilen tarım alanına düşen traktör gücü ( $\mathrm{kW} / \mathrm{ha})$

G2: Bin hektarlık tarım alanına düşen traktör sayısı (traktör/1000 ha)

G3: Traktör başına düşen tarım alanı (ha/traktör)

G4: Traktör başına düşen alet-makine sayısı (Alet-makine/traktör)

G5: Ortalama traktör gücü $(\mathrm{kW})$

G6: Bin hektarlık tarım alanına düşen biçerdöver sayısı (Biçerdöver/1000 ha)

Bu çalışmada tarımsal mekanizasyon gösterge değerlerinin hesaplanmasında tarım alanı olarak ekilen tarım alanı, alet-makine sayıları belirlenirken ise TUİK tarafindan rapor edilen 76 alet-makine arasından traktör ile birlikte kullanılan 46 tanesi kullanılmıştır. Orta Anadolu bölgesi illeri için yıllara bağlı toplam tarım alanı değerleri Tablo 1'de verilmiştir.

Tablo 1. Orta Anadolu bölgesi illeri için toplam tarım alanı (ha)*

\begin{tabular}{lrrrrrrrrrr}
\hline & $\mathbf{2 0 0 5}$ & $\mathbf{2 0 0 6}$ & $\mathbf{2 0 0 7}$ & $\mathbf{2 0 0 8}$ & $\mathbf{2 0 0 9}$ & $\mathbf{2 0 1 0}$ & $\mathbf{2 0 1 1}$ & $\mathbf{2 0 1 2}$ & $\mathbf{2 0 1 3}$ & $\mathbf{2 0 1 4}$ \\
Kayseri & 661098 & 660362 & 616792 & 609762 & 609716 & 603206 & 616169 & 622122 & 604766 & 600260 \\
Kırşehir & 429323 & 426751 & 412481 & 367371 & 349872 & 397711 & 406391 & 399688 & 384531 & 365026 \\
Nevşehir & 325318 & 321423 & 330421 & 330460 & 320952 & 324159 & 329890 & 341528 & 331221 & 333160 \\
Niğde & 270833 & 268234 & 265133 & 263805 & 264010 & 267090 & 269725 & 290269 & 277936 & 278614 \\
Sivas & 801679 & 714407 & 679752 & 552861 & 1059358 & 958876 & 729828 & 771865 & 798231 & 807161 \\
Yozgat & 766963 & 747819 & 731190 & 726969 & 645316 & 739557 & 749325 & 698598 & 599142 & 630029 \\
Aksaray & 414377 & 433970 & 426014 & 396072 & 405867 & 412653 & 389604 & 375266 & 385051 & 415333 \\
Kırıkkale & 297073 & 271418 & 286837 & 291712 & 283714 & 290187 & 297148 & 286694 & 305525 & 309039 \\
\hline$*$ TUiK, 2015a & & & & & & & & &
\end{tabular}

Tablo 1'de verilen değerlerden yola çıkarak toplam tarım alanındaki en küçük değişimin \% 0,23 ile Aksaray ilinde gerçekleştiği belirlenmiştir. TUİK tarafından her bir il için rapor edilen 2005 ve 2014 yıllarına ait değerlerin kullanılmasıyla yapılan hesaplamalar sonrasında; toplam tarım alanında meydana gelen en yüksek azalışın \% 17,85 ile Yozgat ilinde, en büyük artışın ise \% 4,03 ile Kırıkkale ilinde gerçekleştiği saptanmıştır. Yozgat ilinde tarım alanlarında meydana gelen ciddi azalışın; şehirdeki sulama şebekesinin yetersizliği, sulanabilir tarım alanlarının toplam tarım alanının küçük bir bölümünü oluşturması, tarımsal alanların çok parçalı ve küçük olması, köyden kente gerçekleşen göçler ve kırsal 
kesimde çalışan nüfusun ortalama yaşının 50'yi bulması gibi unsurlara bağlı olduğu dikkate alınabilir [8]. Diğer yandan Kırıkkale ilinde meydana gelen artışta; Gıda, Tarım ve Hayvancılık Bakanlığının, Kırsal Kalkınma Yatırımlarının Desteklenmesi Programı Kapsamında son yıllarda verilen hibe ve desteklerin etkili olduğu söylenebilir [9]. Orta Anadolu bölgesi illeri için ekilen tarım alanı değerleri aşağıda Tablo 2' de verilmiştir.

Tablo 2. Orta Anadolu bölgesi illeri için ekilen tarım alanı (ha)*

\begin{tabular}{lrrrrrrrrrr}
\hline & $\mathbf{2 0 0 5}$ & $\mathbf{2 0 0 6}$ & $\mathbf{2 0 0 7}$ & $\mathbf{2 0 0 8}$ & $\mathbf{2 0 0 9}$ & $\mathbf{2 0 1 0}$ & $\mathbf{2 0 1 1}$ & $\mathbf{2 0 1 2}$ & $\mathbf{2 0 1 3}$ & $\mathbf{2 0 1 4}$ \\
Kayseri & 661098 & 660362 & 616792 & 609762 & 609716 & 603206 & 616169 & 622122 & 604766 & 345280 \\
Kırşehir & 429323 & 426751 & 412481 & 367371 & 349872 & 397711 & 406391 & 399688 & 384531 & 235125 \\
Nevşehir & 325318 & 321423 & 330421 & 330460 & 320952 & 324159 & 329890 & 341528 & 331221 & 228155 \\
Niğde & 270833 & 268234 & 265133 & 263805 & 264010 & 267090 & 269725 & 290269 & 277936 & 160021 \\
Sivas & 801679 & 714407 & 679752 & 552861 & 1059358 & 958876 & 729828 & 771865 & 798231 & 489828 \\
Yozgat & 766963 & 747819 & 731190 & 726969 & 645316 & 739557 & 749325 & 698598 & 599142 & 454846 \\
Aksaray & 414377 & 433970 & 426014 & 396072 & 405867 & 412653 & 389604 & 375266 & 385051 & 249117 \\
Kırıkkale & 297073 & 271418 & 286837 & 291712 & 283714 & 290187 & 297148 & 286694 & 305525 & 177626 \\
\hline * TUiK, 2015a & & & & & & & & &
\end{tabular}

Tablo 2'de verilen değerler incelendiğinde ise, ekilen tarım alanlarının tüm iller genelinde azaldığı fark edilmektedir. En yüksek alan kaybının \% 47,77 ile Kayseri ilinde, en düşük alan kaybının ise \% 29,87 ile Nevşehir ilinde gerçekleştiği tablodaki verilerden yola çıkılarak hesaplanmıştır.

\section{Bulgular}

Tarımsal mekanizasyon düzeyinin belirlenmesinde traktör sayılarının ve güç değerlerinin büyük bir öneme sahip olduğu bilinmektedir. Orta Anadolu illeri için farklı güç gruplarında TUiKK tarafindan rapor edilen tek akslı ve iki akslı traktörlere ait değerler aşağıda Tablo 3 ve Tablo 4 'te verilmiştir.

Tablo 3. Orta Anadolu bölgesi için tek akslı traktör sayıları*

\begin{tabular}{rrrrrrrrrrr}
\hline & $\mathbf{2 0 0 5}$ & $\mathbf{2 0 0 6}$ & $\mathbf{2 0 0 7}$ & $\mathbf{2 0 0 8}$ & $\mathbf{2 0 0 9}$ & $\mathbf{2 0 1 0}$ & $\mathbf{2 0 1 1}$ & $\mathbf{2 0 1 2}$ & $\mathbf{2 0 1 3}$ & $\mathbf{2 0 1 4}$ \\
1-5 BG & 112 & 115 & 85 & 143 & 137 & 182 & 389 & 411 & 447 & 477 \\
$>$ 5 BG & 433 & 433 & 483 & 667 & 803 & 962 & 1.981 & 2.113 & 2.113 & 2357 \\
\hline
\end{tabular}

* TUIK, 2015b

Tablo 4. Orta Anadolu bölgesi için iki akslı traktör sayıları*

\begin{tabular}{lrrrrrrrrrr}
\hline & $\mathbf{2 0 0 5}$ & $\mathbf{2 0 0 6}$ & $\mathbf{2 0 0 7}$ & $\mathbf{2 0 0 8}$ & $\mathbf{2 0 0 9}$ & $\mathbf{2 0 1 0}$ & $\mathbf{2 0 1 1}$ & $\mathbf{2 0 1 2}$ & $\mathbf{2 0 1 3}$ & $\mathbf{2 0 1 4}$ \\
$\mathbf{1 - 1 0}$ BG & 66 & 82 & 995 & 993 & 787 & 855 & 760 & 837 & 841 & 854 \\
$\mathbf{1 1 - 2 4}$ BG & 438 & 387 & 584 & 622 & 444 & 458 & 494 & 487 & 497 & 480 \\
25-34 BG & 6196 & 6252 & 6677 & 7030 & 6827 & 6319 & 6013 & 6006 & 5973 & 4743 \\
35-50 BG & 46018 & 47376 & 46559 & 46105 & 45819 & 45707 & 46209 & 46247 & 44498 & 45132 \\
$\mathbf{5 1 - 7 0 ~ B G}$ & 53714 & 55288 & 54578 & 54756 & 54605 & 54758 & 55398 & 56877 & 56239 & 58152 \\
$>$ 70 BG & 6846 & 7876 & 8621 & 8822 & 8593 & 9550 & 10508 & 11362 & 12010 & 13933 \\
\hline * TUIK. 2015b & & & & & & & & & &
\end{tabular}


Tablo 3 incelendiğinde Orta Anadolu illerinde 1-5 BG gücündeki tek akslı traktör sayısının son on yılda yaklaşık dört katına çıktığı, 5 BG den daha yüksek güce sahip olanların sayısındaki artışın ise dört kattan fazla olduğu görülmektedir. Tablo 4 ile verilen iki akslı traktör sayıları incelendiğinde 1-10 BG güç aralığındaki traktör sayısının yaklaşık on üç katına çıktığı fark edilebilir. İki akslı traktör sayılarındaki bir diğer önemli artış ise 70 BG değerinin üzerinde güce sahip traktörlerde olmuştur. Bu tipteki traktör sayılarının son on yılda yaklaşık iki katına çıktığı belirlenmiştir. Diğer yandan sayıca en önemli azalma miktarı 25-34 BG güç aralığında yer alan traktörlerde \% 23,45 olarak hesaplanmıştır. Tablo 5’te Orta Anadolu Bölgesi illeri için biçerdöver sayıları verilmiştir.

Tablo 5. Orta Anadolu bölgesi için biçerdöver sayıları*

\begin{tabular}{lrrrrrrrrrr}
\hline & $\mathbf{2 0 0 5}$ & $\mathbf{2 0 0 6}$ & $\mathbf{2 0 0 7}$ & $\mathbf{2 0 0 8}$ & $\mathbf{2 0 0 9}$ & $\mathbf{2 0 1 0}$ & $\mathbf{2 0 1 1}$ & $\mathbf{2 0 1 2}$ & $\mathbf{2 0 1 3}$ & $\mathbf{2 0 1 4}$ \\
0-5 Yaş & 449 & 589 & 604 & 600 & 635 & 732 & 775 & 799 & 837 & 880 \\
6-10 Yaş & 646 & 680 & 694 & 748 & 728 & 802 & 810 & 893 & 910 & 913 \\
11-20 Yaş & 704 & 675 & 708 & 706 & 725 & 773 & 774 & 873 & 876 & 877 \\
$\geq$ 21 Yaş & 316 & 367 & 376 & 356 & 414 & 436 & 454 & 480 & 457 & 470 \\
\hline * TUíK, 2015b & & & & & &
\end{tabular}

Tablo 5'te yer alan değerlerden yola çıkılarak 2005-2014 y1lları arasında toplam biçerdöver sayısının yaklaşık \% 30 arttığı ve en yüksek artışın yaklaşık \% 96 ile 0-5 yaş aralığındaki biçerdöver sayısında olduğu hesaplanmıştır.

Orta Anadolu illerinde mekanizasyon düzeyindeki değişimin belirlenebilmesi için bölgeye ait tarımsal alan ve makine varlıklarının belirlenmesi gerekmektedir. $\mathrm{Bu}$ amaçla ortalama traktör gücü değerlerinin hesaplanmasında traktör sayıları ve güç değerleri birlikte kullanılmıştır. Tablo 6'da verilen alet-makine sayıları belirlenirken TUİK tarafindan rapor edilen 76 alet-makine arasından traktör ile birlikte kullanılan 46 tanesi kullanılmıştır.

Tablo 6. Orta Anadolu bölgesi için tarımsal alan ve makine varlıkları*

\begin{tabular}{lrrrrrrrrrr}
\hline & $\mathbf{2 0 0 5}$ & $\mathbf{2 0 0 6}$ & $\mathbf{2 0 0 7}$ & $\mathbf{2 0 0 8}$ & $\mathbf{2 0 0 9}$ & $\mathbf{2 0 1 0}$ & $\mathbf{2 0 1 1}$ & $\mathbf{2 0 1 2}$ & $\mathbf{2 0 1 3}$ & $\mathbf{2 0 1 4}$ \\
$\begin{array}{l}\text { Ortalama traktör } \\
\text { gücü (kW) }\end{array}$ & 39,32 & 39,53 & 39,33 & 39,28 & 39,33 & 39,55 & 39,46 & 39,64 & 39,85 & 40,38 \\
$\begin{array}{l}\text { Toplam tarım alanı } \\
\text { (1000 ha) }\end{array}$ & 3966 & 3844 & 3748 & 3539 & 3938 & 3993 & 3788 & 3786 & 3686 & 3738 \\
$\begin{array}{l}\text { Ekilen tarım alanı } \\
\text { (1000 ha) }\end{array}$ & 2548 & 2486 & 2474 & 2336 & 2410 & 2484 & 2368 & 2361 & 2270 & 2339 \\
$\begin{array}{l}\text { Alet-makine } \\
\text { (adet) }\end{array}$ & 564998 & 574641 & 577635 & 577722 & 595939 & 610825 & 622463 & 633220 & 639587 & 654106 \\
$\begin{array}{l}\text { Traktör sayısı } \\
\text { (adet) }\end{array}$ & 113823 & 117809 & 118582 & 119138 & 118015 & 118791 & 121752 & 124340 & 122618 & 126128 \\
$\begin{array}{l}\text { Biçerdöver sayısı } \\
\text { (adet) }\end{array}$ & 2115 & 2311 & 2382 & 2410 & 2502 & 2743 & 2813 & 3045 & 3080 & 3140 \\
\hline$*$ TUiK, 2015a, 2015b & & & & & & &
\end{tabular}

* TUİK, 2015a, 2015b

Tablo 6'da verilen değerlerde 2005-2014 yılları arasında meydana gelen yüzde değişim miktarları hesaplandığında; toplam ve ekilen tarım alanlarında azalma oranları sırasıyla \% 5,75 ve \% 8,20 olduğu görülmüştür. Buna karşılık yüzde artış değerleri ortalama traktör gücünde \% 2,70, alet-makine sayısında \% 15,77, traktör sayısında \% 10,81, biçerdöver sayısında \% 48,46 olarak belirlenmiştir. Tablo 7'de elde edilen tüm verilerin işlenmesi sonrasında hesaplanan tarımsal mekanizasyon gösterge değerlerinin son on yıldaki değişimi ortaya konulmuştur 
.Tablo 7. Orta Anadolu bölgesinde tarımsal mekanizasyon düzeyi*

\begin{tabular}{lrrrrrrrrrr}
\hline & $\mathbf{2 0 0 5}$ & $\mathbf{2 0 0 6}$ & $\mathbf{2 0 0 7}$ & $\mathbf{2 0 0 8}$ & $\mathbf{2 0 0 9}$ & $\mathbf{2 0 1 0}$ & $\mathbf{2 0 1 1}$ & $\mathbf{2 0 1 2}$ & $\mathbf{2 0 1 3}$ & $\mathbf{2 0 1 4}$ \\
G1 (kW/ha) & 1,76 & 1,87 & 1,88 & 2,00 & 1,93 & 1,89 & 2,03 & 2,09 & 2,15 & 2,18 \\
G2 (traktör/1000 ha) & 44,66 & 47,39 & 47,92 & 50,99 & 48,95 & 47,81 & 51,40 & 52,65 & 53,99 & 53,90 \\
G3 (ha/traktör) & 22,39 & 21,10 & 20,87 & 19,61 & 20,43 & 20,92 & 19,45 & 18,99 & 18,52 & 18,55 \\
G4 (Alet-makine/traktör) & 4,96 & 4,88 & 4,87 & 4,85 & 5,05 & 5,14 & 5,11 & 5,09 & 5,22 & 5,19 \\
G5 (kW) & 39,32 & 39,53 & 39,33 & 39,28 & 39,33 & 39,55 & 39,46 & 39,64 & 39,85 & 40,38 \\
G6 (Biçerdöver/1000 ha) & 0,83 & 0,93 & 0,96 & 1,03 & 1,04 & 1,10 & 1,19 & 1,29 & 1,36 & 1,34 \\
\hline * TUíK, 2015 a, 2015b & & & & & & & & & &
\end{tabular}

Tablo 7'de değişimi önem arz eden parametrelerin değişimlerinin daha kolay anlaşılabilmesi için aşağıda şekiller verilmiştir. Şekil 1' de Orta Anadolu illerinde birim ekilen tarım alanına düşen traktör gücünün son on yıldaki değişimini ifade etmektedir. Tablo 7'de yer alan verilerden yola çıkarak güç değerindeki artış oranının \% 24 olduğu hesaplanmıştır. Şekil 1 incelendiğinde 2008 ve 2010 yılları dışında güç artışının doğrusala yakın bir karakterde gerçekleştiği görülmektedir.

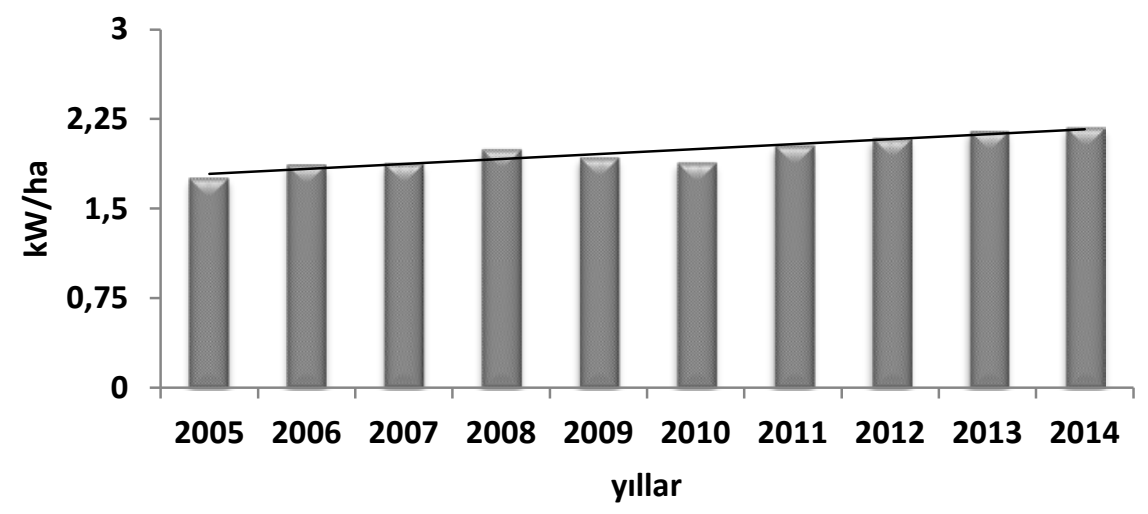

Şekil 1. Birim ekilen tarım alanına düşen traktör gücü

Şekil 2'de traktör başına düşen tarım alanındaki değişim verilmiştir. Artan traktör sayısına ve azalan tarım alanına bağlı olarak bu değerde meydana gelen azalma oranı ise yaklaşı \% 17 olarak belirlenmiştir. 2008 ve 2010 yılları dışında traktör başına düşen tarım alanı doğrusal bir şekilde azalmaya devam etmiştir.

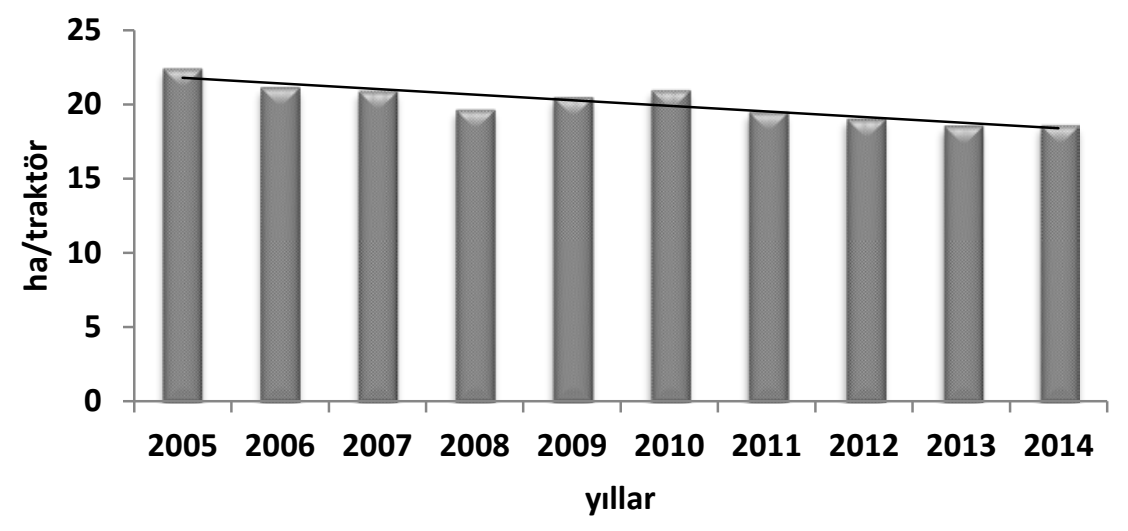

Şekil 2. Traktör başına düşen tarım alanı 
Şekil 3' te ortalama traktör gücündeki değişim yer almaktadır. 2005 yılında 39,32 kW değerindeki traktör gücü yaklaşık \% 3 oranında bir artış ile 40,38 kW değerine ulaşmıştır. 2006 ve 2014 yıllarında artışın diğer yıllara göre daha yüksek bir oranda gerçekleştiği görülmektedir.

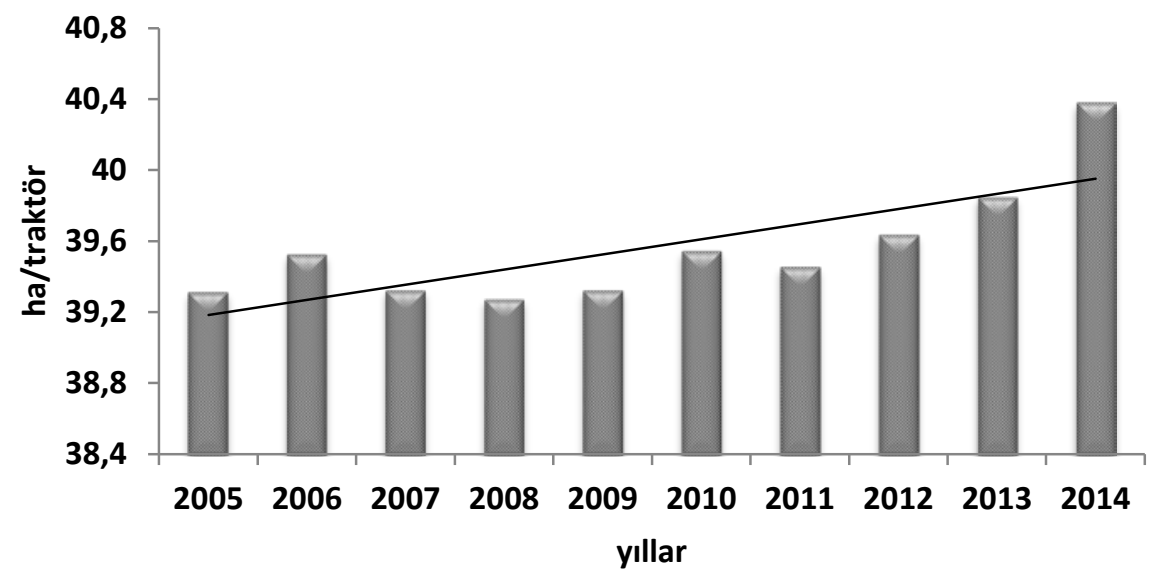

Şekil 3. Ortalama traktör gücü

\section{Tartışma ve Sonuç}

Türkiye geneli dikkate alındığında tarımsal mekanizasyon düzeyi göstergeleri yaklaşık olarak şu şekildedir. Birim ekilen tarım alanına düşen traktör gücü 2,91 kW/ha, 1000 ha' lık tarım alanına düşen traktör sayısı 71 traktör/1000 ha, traktör başına düşen tarım alanı 14,08 ha/traktör, traktör başına düşen alet-makine sayısı 6,32 Alet-makine/traktör, Ortalama traktör gücü 41 kW, 1000 ha' lık tarım alanına düşen biçerdöver sayısı 0,9 Biçerdöver/1000 ha'dır [3]. Bu değerler çalışmada elde edilen değerler ile karşılaştırıldığında Orta Anadolu bölgesinde; Birim ekilen tarım alanına düşen traktör gücünün, bin hektara düşen traktör ve traktör başına düşen alet-makine sayısının Türkiye ortalamasının altında kaldığı görülmektedir. Ortalama traktör güç değerinin Türkiye ortalamasına çok yakın olduğu ve bin hektara düşen biçerdöver sayısı değerinin ise Türkiye ortalamasının üzerinde olduğu belirlenmiştir. Sonuç olarak; bölgede tarımsal mekanizasyon düzeyinin son on yıl boyunca yükseldiği görülmektedir. Diğer yandan dünya ve ülkemiz genelinde ulaşılan tarımsal mekanizasyon düzeyi dikkate alındığında, mekanizasyon düzeyini artırmaya yönelik çalışmaların artarak devam etmesinin uygun olacağı görülmektedir.

\section{Kaynaklar}

[1] Anonim, Tarım Makineleri Sektör Raporu, Batı Akdeniz Kalkınma Ajansı, 2012

[2] Baran M.F., Gökdoğan O., Durgut M.R., "Batı Marmara Bölgesi'nin Tarımsal Mekanizasyon Özellikleri”, Türk Tarım ve Doğa Bilimleri Dergisi, 1(4): 561-567, 2014

[3] Anonim, "Diyarbakır İli Tarımsal Mekanizasyon Durum Analizi ve Planlaması Projesi", Dicle Üniversitesi Ziraat Fakültesi Tarım Makinaları Bölümü, 51s, Diyarbakır, 2012

[4] Özgüven M.M., Türker U., Beyaz A., "Türkiye'nin Tarımsal Yapısı ve Mekanizasyon Durumu”, Gaziosmanpaşa Üniversitesi, Ziraat Fakültesi Dergisi, 28(2), 89-100, 2010

[5] İleri M.S,, Sektör Raporu, Türkiye Tarım Makinaları Sektörü, TARMAKBİR Türk Tarım Alet ve Makinaları İmalatçıları Birliği, 2014 
[6] Altuntaş E., Demirtola H., "Ülkemizin Tarımsal Mekanizasyon Düzeyinin Coğrafik Bölgeler Bazında Değerlendirilmesi”, GOÜ. Ziraat Fakültesi Dergisi, 21(2): 63-70, 2004

[7] Gürsoy S., "Batman İlinin Tarımsal Mekanizasyon Düzeyinin İlçeler Bazında Değerlendirilmesi”, Batman Üniversitesi Yaşam Bilimleri Dergisi, 3(2): 146-158, 2013

[8] Anonim, Yozgat Tarım Hayvancılık ve Gıda Sektörel Çalışma Grubu Raporu, 2011

[9] Anonim, Tarım Bülteni, Kırıkkale İl Gıda Tarım ve Hayvancılık Müdürlüğü, sayı 4, 2014 TÜİK, 2015a. Web sitesi. Bitkisel Üretim İstatistikleri. http://tuikapp.tuik.gov.tr/bitkiselapp/bitkisel.zul (Erişim Tarihi: 08.06.2015)

[10] TÜİK, 2015b. Web sitesi. Tarımsal Alet ve Makina Sayıları http://tuikapp.tuik.gov.tr/bitkiselapp/tarimalet.zul (Erişim Tarihi: 16.06.2015) 